International Journal of Linguistics, Literature and Translation

ISSN: 2617-0299 (Online); ISSN: 2708-0099 (Print)

DOI: $10.32996 / \mathrm{ijllt}$

Journal Homepage: www.al-kindipublisher.com/index.php/ijltt

IJLLT

\title{
An Investigation into Learners' Perception Towards Peer Assessment in Tertiary EFL Writing Class
}

\author{
Nguyen Ngoc Huy \\ Faculty of Foreign Languages, Van Lang University, Vietnam \\ $\square$ Corresponding Author: Nguyen Ngoc Huy, E-mail: huy.nn@vlu.edu.vn
}

\begin{abstract}
ARTICLE INFORMATION ABSTRACT
Received: 02 August 2021

Accepted: 02 December 2021

Published: 07 December 2021

DOI: 10.32996/ijllt.2021.4.12.2

\section{KEYWORDS}

Peer assessment, reflection, academic writing

The current paper attempts to investigate learners' perspectives towards the strengths and weaknesses of peer assessment in academic writing in the context of tertiary education at a private university. The study was conducted on 55 third-year university students who had finished the academic writing module that applied peer assessment in writing. The research adopted the mixed method of qualitative and quantitative approaches via the questionnaire with both close and open-ended questions. The results of the study reveal that the use of peer assessment was feasible for large-size classes at university to provide learners with the opportunities to reflect and enhance their language scope and social knowledge to improve their writing performance. However, certain limitations were acknowledged, such as the lack of assessment competence among learners and the time constraint in the classroom, especially the hesitation to violate the positive face of their peers.
\end{abstract}

\section{Introduction}

The effectiveness of teaching writing has spurred a notable interest among scholars and teachers in several contexts of English teaching. Writing is supposed to be the most complicated skill in second language acquisition as it requires not only linguistic competence but also intercultural and discourse competence among learners (Richards \& Renandya, 2002). Hence, writing acquisition requires a variety of sub-skills to empower learners' performance in academic writing. The dominance of writing activities is on teachers who act as the center of the class. However, this prejudice is not appropriate in the current context of globalization. The recent years have witnessed a transformation from teacher-centered approaches to learner-centeredness in the sector of language education. Therefore, learners' participation is increasingly encouraged in ELT.

The improvement of academic performance also involves learners' capacity to review and assess the quality of other peers' papers to determine the strengths and weaknesses of other papers (Hyland, 2000; Xiang, 2004). As a result, peer assessment is adopted to maximize the effectiveness of cooperative learning and reduce the dependence on teachers in writing classes. This alternative formative assessment is promising to enhance learners' competence via a shared understanding of social and linguistic knowledge with a certain positive experience from participants (Jahin, 2012).

\subsection{Statement of the problem}

In the context of the Faculty of Foreign Languages, Van Lang University, the implementation of peer assessment in academic writing has been made to show certain positive results in terms of academic improvement. However, the results are not equal in all classes as well as among students. In addition, some students do not express positive attitudes towards the use of peer assessment. It leads to the confusion of teachers on the extent of the appropriateness of peer assessment and difficulties in the application of this form of alternative assessment.

\subsection{Research questions}

To address the aforementioned issue, the following research question is proposed:

What are learners' perspectives towards the use of peer assessment in academic writing?

Copyright: (c) 2021 the Author(s). This article is an open access article distributed under the terms and conditions of the Creative Commons Attribution (CC-BY) 4.0 license (https://creativecommons.org/licenses/by/4.0/). Published by Al-Kindi Centre for Research and Development, London, United Kingdom. 


\subsection{Scope of the study}

This study aims to investigate the perspectives of third-year students who major in English towards the strengths and the weaknesses of the implementation of peer assessment in academic writing classes they have experienced at the Faculty of Foreign Languages, Van Lang University. Moreover, the study aims to understand learners' preferences in writing assessments for academic purposes, which may bring about positive effects for their learning process. The writing courses are based on IELTS templates with the expected learning outcomes of B2 in Common European Framework for Reference. The coursebook was Mindset for IELTS Level 2 (Archer, G., 2017). The writing criteria consist of task achievement, grammatical range and accuracy, lexical resource, and coherence and cohesion.

\section{Literature review}

\subsection{The concept of peer assessment}

Peer assessment is considered as an alternative formative assessment, in which learners participate in giving feedback and assess the standard of the academic papers written by other learners of the same level in the same academic context (Topping, 2008). It is also known as the opportunity for learners to take an active role in the exchange of useful feedback in the learning process (Cho $\&$ Cho, 2011). It requires the learners to base on a particular holistic or analytic grading scale to give comments for their friends about the performance expressed in the product.

In addition, peer assessment is used interchangeably with similar terms such as peer evaluation, peer review, or critique throughout the communication process outside or outside the class (Liu \& Carless, 2006). This accelerates the sense of collaboration among learners to negotiate the performance of each other to propose the most appropriate decision towards the version of products. As a consequence, the quantity of exposure to language can be strengthened to maximize the effectiveness of second language acquisition (Van et al., 2010). This idea is correlated with Vygotsky's Zone of Proximal Development as learners can obtain higher performance with the assistance of their peers (Vygotsky, 1978).

A range of identities has been identified to moderate the effectiveness of peer assessment, such as anonymity (Yu \& Liu, 2009), scaffolding ( Panadero \& Jonsson, 2013), quality and time allocation of the feedback (Diab, 2011), and elaboration (Gielen et al., 2010). These characteristics are vital to manipulate the efficacy of the peer assessment in particular pedagogical contexts.

\subsection{Benefits of peer assessment in academic writing}

The application of peer assessment in academic writing has shown several significant values in second language teaching. The main reason is that peer assessment is a beneficial way for learners to assess the learning output of what others have achieved in their voice after the course (Hounsell, 1997). In the negotiation of other work, it is possible to reduce the overestimation and underestimation of the quality of personal work from self-assessment (Sung et al., 2010).

In addition, the involvement in assessing the strengths and weaknesses of other learners contributes to the reflection of learners' self-regulation to raise their awareness of personal roles as learning autonomy (Chew et al., 2014; Mo, 2007; Wu, 2013). When learners read and evaluate the product of other peers, they can (1) gain more insights into the interpretation of the writing rubrics to achieve certain levels and (2) realize the mistakes of the peers to avoid in further study. This model is also helpful to address wrong personal assumptions on the use of grammatical structures and lexical resources. Moreover, peer assessment is thought to reduce the degree of dependence on teachers via self-reflection and evaluation and enhance confidence among learners to monitor their learning process (Carnell, 2016; Liu \& Carless, 2006)

In a study conducted by Cheng et al. (2015), the research showed that online peer assessment with cognitive feedback was influential on students' writing performance. The understanding and discussion of social issues were identified with critical thinking capacity among university students. Another study by Fristiara et al. (2018) showed positive attitudes from learners towards the implementation of peer assessment in writing of higher education when they could evaluate the strong and weak points in writing.

\subsection{Problems of peer assessment in academic writing}

Despite the dramatic values, peer assessment also poses certain limitations in reality. First, peer assessment is more suitable for learners with more experience to give sufficient constructive feedback to their peers. Students of low levels cannot understand the rubrics and possess enough knowledge and skill to evaluate their mates' papers (Hattie \& Timperley, 2007). Second, this model demands a long period of training for teachers to organize the classroom activities and those outside the class as well as training for students on the principles to give feedback to their peers (Zhao, 2014, as cited in Shen, 2020).

Another important point for an assertion is that learners need to be at a certain level of proficiency and professionalism to conduct peer assessment (Athan, 2014). The lack of professional and profound understanding of the subject matters leads to the incapacity to give constructive feedback among learners. The explanation of grammatical or lexical issues is only on the surface of the matter. Hence, learners' cannot provide significant recommendations for their friends to improve writing performance with teachers' 
assumptions (Zhao, 2010). Finally, some learners show negative attitudes towards peer assessment due to their hesitation to have power over their friends and refuse to hurt their peers (Yu, 2016).

\section{Methodology}

\subsection{Setting and participants}

The study was conducted with the participation of 55 fourth-year students of Business English who studied IELTS Academic Writing as a compulsory core subject at the Faculty of Foreign Languages, Van Lang University. The competence of students at the time of the study was approximately B2 in CEFR. The total number of 55 participants was equal to the average class size to represent the similar classes of this research site. However, only 54 responses were returned in the research instrument.

\subsection{Methods}

The combination of qualitative and quantitative approaches was implemented in the study to investigate objective and subjective elements in the application of different teaching methods. The mixed approach is regarded to have higher levels of accuracy and reliability of data with the analysis of various factors that influence the results of the study (Denscombe, 2017).

The participant demographic was described in the following table

Table 1. Research Participants' Demographics $(\mathbf{N}=54)$

\begin{tabular}{llll}
\hline Age & 22 & & \\
\hline \multirow{2}{*}{ Gender } & & Number & Percentage \\
\cline { 2 - 4 } & Male & 10 & $18.5 \%$ \\
\cline { 2 - 4 } & Female & 44 & $81.5 \%$ \\
\hline
\end{tabular}

\subsection{Instruments}

\section{Questionnaire}

The survey was conducted with two main parts of multiple choice and open questions. In the first section of the survey, the fourpoint Likert scale to investigate the extent of students' perspective on the agreement with 20 statements relating to the benefits and drawbacks of peer assessment in academic writing. The omission of the middle neutral one on the scale is because neutrality may lead to indecisive choices (Revila, 2013). There are also two open questions for respondents to express their personal opinion towards the application of peer assessment. An additional Vietnamese version of the questionnaires was available to ensure the participants were able to understand the questionnaire. In addition, the reliability and validity of the questionnaires were ensured with the adaptation of Gencha's questionnaire (2018).

\section{Interview}

Ten respondents were chosen for a short 15-minute interview to understand the reasons and further ideas of the participants in the study. The interview was recorded and transcribed into words for further analysis.

\subsection{Sampling procedure}

A total number of 54 participants were chosen as the convenience samples to reduce the time of randomization of the samples. The samples were also encoded from A1 to A54 to assure the objectivity of the researcher in the study.

\subsection{Data collection and analysis}

The questionnaire was delivered to participants on Google form for convenient and economical purposes. Primarily, the study targeted 55 participants, but only 54 responses were returned for analysis. After the collection of the questionnaires, an interview for a more profound understanding was conducted to figure out participants' perceptions.

The four-point Likert scale was coded for statistical analysis as follows.

Table 2. Mean Value Equivalence

\begin{tabular}{|l|l|l|l|l|}
\hline No. & Perception & Numeral Scale & Weighted Mean & Interpretation \\
\hline 1 & Strongly Disagree & 1 & $1.00-1.75$ & Low \\
\hline 2 & Disagree & 2 & $1.76-2.50$ & Moderate \\
\hline 3 & Agree & 3 & $2.51-3.25$ & High \\
\hline 4 & Strongly Agree & 4 & $3.26-4.00$ & Very high \\
\hline
\end{tabular}




\section{Findings and discussion}

Table 3. Students' perceptions of peer assessment in academic writing $(\mathbf{N}=54)$

\begin{tabular}{|c|c|c|c|}
\hline No. & Survey Questions & Mean & S.D \\
\hline 1 & Peer assessment is time-consuming & 2.70 & 0.57 \\
\hline 2 & Peer assessment requires too much for teachers' preparation & 2.57 & 0.63 \\
\hline 3 & Peer assessment requires teachers to train learners on criteria & 2.98 & 0.60 \\
\hline 4 & Students are not willing to do peer assessment & 2.65 & 0.70 \\
\hline 5 & Peer assessment may be offensive & 2.69 & 0.70 \\
\hline 6 & Learners do not have enough time for peer assessment & 2.65 & 0.65 \\
\hline 7 & Peer assessment enhances learners' autonomy & 2.69 & 0.70 \\
\hline 8 & Peer assessment enhances learners' engagement & 3.04 & 0.43 \\
\hline 9 & Peer assessment enhances learners' competence in writing & 3.00 & 0.43 \\
\hline 10 & Learners can share social and cultural knowledge in peer assessment & 3.09 & 0.59 \\
\hline 11 & Learners can realize their mistakes to enhance self-assessment & 3.07 & 0.58 \\
\hline 12 & Learners can discuss with peers to understand the feedback & 3.20 & 0.56 \\
\hline 13 & Learners can negotiate the version of their writing with peers & 3.15 & 0.53 \\
\hline 14 & Learners can avoid mistakes they may cause from their friends' papers & 3.24 & 0.58 \\
\hline 15 & Learners can enhance knowledge in reading other papers & 3.22 & 0.60 \\
\hline 16 & Learners can expand their vocabulary & 3.28 & 0.53 \\
\hline 17 & Learners can expand their grammatical structures & 3.17 & 0.61 \\
\hline 18 & Learners can gain insights into the expression & 3.13 & 0.62 \\
\hline 19 & Learners can read sample writing from their friends' style & 3.15 & 0.53 \\
\hline 20 & Learners can learn logical order of ideas & 3.11 & 0.54 \\
\hline
\end{tabular}

Table 3. represents the mean score and standard deviation of the survey on learners' perspective towards the chances and challenges in the application of peer assessment via the adoption of a four-point Likert scale. The data collected from the questionnaire showed that the participants expressed positive attitudes towards the use of peer assessment in academic writing. The chart also indicates the general agreement of the participants with 20 question items from the questionnaire. The mean score ranged from 2.57 in the limitation of question item No.2 to 3.38 in question item No. 16. The standard deviation was statistically significant, ranging from 0.43 to 0.70 .

This means that the application of peer assessment can result in positive effects for students' academic writing competence in the majority of statements. The most noticeable benefit refers to the improvement of vocabulary when learners read the papers of their peers and learn the vocabulary via their expression in writing. Moreover, the second significant value belongs to the ability to avoid mistakes when learners can evaluate to identify their friends' weaknesses in academic writing to deepen their knowledge and avoid in the future.

On the contrary, participants show the least agreement on the consumption of teachers' preparation. This is because peer assessment shifts the control of the learning process from teachers to students. Hence, it reduces the number of time teachers spends on marking and giving feedback for individual papers. The application of this model requires learners to spare more time outside the class to give comments to their friends in comparison with teacher feedback.

The interview of 15 students also revealed additional information about the attitudes of learners in peer assessment. Regarding the chance of peer assessment, students can develop their writing style by reading their friends' paper

A12: learners can seek their style of writing through their friends' articles.

A21: Freedom of writing skill 
A29: Create personal ideas in the style of his words.

Peer assessment is also beneficial for learners to formulate the learning spirit and self-responsibility

A37: The other benefit of peer assessment is reduced learner inferiority. Increase the spirit of learning in friends.

A43: Helps students develop their judgmental skills when they work in a group

A47: Helps students develop lifelong skills in assessing and providing feedback to others, and also equips them with skills to self-assess and improve their work.

On the contrary, certain limitations are also added. The mental effects can be caused when learners read their peers' papers. They will be shy to some extent if their competence is not approximately equal. Moreover, some learners are not qualified or knowledgeable enough to mark their friends' products.

A11: Causing comparison leads to impacts the mental of the peers in the learning process

A23: It is possible that the reviewer does not fully understand or is not knowledgeable

A51: Other limitations of peer assessment in writing are inadequate accuracy and objectivity.

\section{Implication and conclusion}

The study is of significance to investigate learners' attitudes towards the implementation of peer assessment in academic writing. First, teachers should spend more time understanding their learners' characteristics to shape the way they apply peer assessment to reduce subjective assumptions on learners. Second, the results indicate that learners are willing to experience peer assessment to enhance academic writing performance. Third, learner autonomy and the sense of responsibility can be enhanced in the peer assessment via the construction of life long learning spirit among students. Finally, learners' difficulties in peer assessment should be taken into consideration to create the appropriate learning environment for learners. In brief, peer assessment is promising in the academic writing context to enhance learners' competence with positive attitudes. However, further studies are recommended to minimize the difficulties learners experience in this alternative formative assessment.

\section{References}

[1] Cheng, K., Liang, J. \& Tsai C. (2015). Examining the role of feedback messages in undergraduate students' writing performance during an online peer activity. Internet and Higher Education, 25, 78-84.

[2] Cheng, W., \& Warren, M. (2005). Peer assessment of language proficiency. Language Testing, 22(1), 93-121.

[3] Chew, E., Snee, H., \& Price, T. (2014). Enhancing international postgraduates' learning experience with online peer assessment and feedback innovation. Innovations in Education and Teaching International, 53(3), 247-259.

[4] Cho, Y. H. , \& Cho, K. (2011). Peer reviewers learn from giving comments. Instructional Science, 39(5), $629-664$.

[5] Conrad, S. M., \& Goldstein, L. M. (1999). ESL student revision after teacher-written comments: Text, contexts, and individuals. Journal of Second Language Writing, 8(2), 147-179.

[6] Fritiara, C., Sumardi \& Drajati, N. A. (2018). Self-assessment: Its roles for higher

[7] education students in academic writing class. ELS Journal on Interdisciplinary Studies on Humanities, 1(3): 357-365

[8] Hattie, J., \& Timperley, H. (2007). The power of feedback. Review of Educational Research, 77(1), 81-112.

[9] Hyland, F.(2000). ESL writers and feedback: Giving more autonomy to students. Language Teaching Research, 4(1),33-54.

[10] Jahin, J. H. (2012). The Effect of Peer Reviewing on Writing Apprehension and Essay Writing Ability of Prospective EFL Teachers. Australian Journal of Teacher Education, 37(11), $\mathrm{n} 11$.

[11] Liu, N.-F., \& Carless, D. (2006). Peer feedback: The learning element of peer assessment. Teaching in Higher Education, 11(3), $279-290$.

[12] Mo, J. (2007). Peer review: Increasing student autonomy in writing. Journal of PLA University of Foreign Languages, 30(3), 35-39.

[13] Mulder, R.A.,(2014). Peer review in higher education: Student perceptions before and after participating. Peer review in higher education: Student perceptions before and after participation Active Learning in Higher Education, 15(2), 157- 171.

[14] Revilla, M., Saris, W. E., \& Krosnick, J. (2013). Choosing the Number of Categories in Agree-Disagree Scales. Sociological Methods \& Research, 43(1), 73-97. http://doi.org/10.1177/0049124113509605

[15] Richards, J. C. \& Renandya, W. A. (2002). Methodology in Language Teaching: An Anthology of Current Practice. New York: Cambridge University Press.

[16] Sitthiworachart, J., \& Joy, M. (2004). The evaluation of students' marking in web-based peer assessment of learning computer programming. In Proceedings of the International Conference on Computers in Education (ICCE 2004) (pp. 1153-1163). Melbourne, Australia.

[17] Sung, Y-T., Chang, K-E., Chang, T.-H., Yu, W.-C. (2010). How many heads are better than one? The reliability and validity of teenagers' selfand peer assessments. Journal of Adolescence, 33, 135- 145.

[18] Topping, K. (2009). Peer assessment. Theory into Practice, 48(1), 20-27.

[19] Vygotsky, L.S (1978). Mind in Society: The Development of Higher Psychological Processes. Cambridge, Massachusetts \& London: Harvard University Press. 


\section{APPENDIX}

\section{Questionnaire}

1. What is your full name?

2. What is your gender?

A. Male

B. Female

3. What is your ID?

4. What is your perspective towards the following statement about the application of peer assessment in academic writing?

\begin{tabular}{|c|c|c|c|c|c|}
\hline $\begin{array}{l}\text { No } \\
\text {. }\end{array}$ & Survey Questions & $\begin{array}{l}\text { Strongly } \\
\text { Disagree }\end{array}$ & Disagree & Agree & $\begin{array}{l}\text { Strongly } \\
\text { Agree }\end{array}$ \\
\hline 1 & Peer assessment is time-consuming & & & & \\
\hline 2 & Peer assessment requires too much for teachers' preparation & & & & \\
\hline 3 & Peer assessment requires teachers to train learners on criteria & & & & \\
\hline 4 & Students are not willing to do peer assessment & & & & \\
\hline 5 & Peer assessment may be offensive & & & & \\
\hline 6 & Learners do not have enough time for peer assessment & & & & \\
\hline 7 & Peer assessment enhances learners' autonomy & & & & \\
\hline 8 & Peer assessment enhances learners' engagement & & & & \\
\hline 9 & Peer assessment enhances learners' competence in writing & & & & \\
\hline 10 & $\begin{array}{l}\text { Learners can share social and cultural knowledge in peer } \\
\text { assessment }\end{array}$ & & & & \\
\hline 11 & Learners can realize their mistakes to enhance self-assessment & & & & \\
\hline 12 & Learners can discuss with peers to understand the feedback & & & & \\
\hline 13 & Learners can negotiate the version of their writing with peers & & & & \\
\hline 14 & $\begin{array}{l}\text { Learners can avoid mistakes they may cause from their friends' } \\
\text { papers }\end{array}$ & & & & \\
\hline 15 & Learners can enhance knowledge in reading other papers & & & & \\
\hline 16 & Learners can expand their vocabulary & & & & \\
\hline 17 & Learners can expand their grammatical structures & & & & \\
\hline 18 & Learners can gain insights into the expression & & & & \\
\hline 19 & Learners can read sample writing from their friends' style & & & & \\
\hline 20 & Learners can learn logical order of ideas & & & & \\
\hline
\end{tabular}

5. What are other benefits of peer assessment in academic writing?

6. What are other problems of peer assessment in academic writing? 